\title{
Sonography in Acute Ureteric Colic: An Experience in Dhulikhel Hospital
}

\author{
Joshi KS, ${ }^{1}$ Karki S, ${ }^{1}$ Regmi S, ${ }^{1}$ Joshi HN, ${ }^{2}$ Adhikari SP ${ }^{3}$
}

${ }^{1}$ Department of Radiodiagnosis and Imaging

${ }^{2}$ Department of Surgery

${ }^{3}$ Department of Physiotherapy

Dhulikhel Hospital - Kathmandu University Hospital

Kathmandu University School Of Medical Sciences

Dhulikhel, Kavre, Nepal

\section{Corresponding Author}

Kirti Subas Joshi

Department of Radiodiagnosis and Imaging

Dhulikhel Hospital - Kathmandu University Hospital

Kathmandu University School Of Medical Sciences

Dhulikhel, Kavre, Nepal

Email: joshisubas@gmail.com

\section{Citation}

Joshi KS, Karki S, Regmi S, Joshi HN, Adhikari SP. Sonography in Acute Ureteric Colic: an Experience in Dhulikhel Hospital. Kathmandu Univ Med J 2014;45(1):9-15.

\section{ABSTRACT}

\section{Background}

Computed tomography is considered as an imaging modality of choice in acute ureteric colic. However due to concerns regarding radiation exposure, sonograms are re-emerging as imaging methods in such situations.

\section{Objectives}

To evaluate the role of sonography in detection of calculus in acute ureteric colic.

\section{Methods}

Total 384 patients were enrolled. Hydronephrosis was graded as mild, moderate or severe. Calculus was detected as an intraluminal echogenic focus with distal shadowing with twinkling artifact. Number, size and position of the calculi were assessed. Patients were categorized into four groups:I. ureteric colic only II. ureteric colic with hematuria III. ureteric colic with hydronephrosis and IV. ureteric colic with hematuria and hydronephrosis and then the possibility of detection of calculi has been compared among these groups.

\section{Results}

Out of 384 patients, 254 were found to have calculi ranging between $2.7-27 \mathrm{~mm}$. Nineteen had in the pelvis/ pelviureteric junction, 64 in proximal ureter, 125 in distal ureter, 6 at iliac crossing and 40 at vesicoureteric junction. Two hundred forty one had single and 14 had multiple calculi. Calculus detection is easier in category III and IV patients. The sensitivity and specificity of ultrasonography were $87.98 \%$ and $93.07 \%$. Degree of hydronephrosis is strongly correlated with the number of calculi but weakly correlated with the size of the calculus.

\section{Conclusion}

Sonogram can be used in all cases of acute ureteric colic. Hydronephrosis is the most important finding because it paves the way out for the detection of calculus.

\section{KEY WORDS}

Calculus, hydronephrosis, sonography, ureteric colic 


\section{INTRODUCTION}

Acute ureteric colic is one of the worst pain a patient ever experiences in his/her life. Plain radiography, sonography, intravenous urography and computed tomography are the imaging modalities available in such situation. ${ }^{1-4}$ Among these, CT is the imaging modality of choice. ${ }^{5-10}$ USG on the other hand is very handy imaging modality but its capability had been underestimated. ${ }^{11}$ The overall sensitivity and specificity of CT is $95-96 \%$ and $98-100 \% .^{3-10}$ CT is better than IVU in identifying ureteral stones. ${ }^{11}$ It is also better than combined US and plain radiography for detection of ureteric calculi. $^{12}$

But major drawback of CT is radiation exposure. The lifetime risk of developing a malignancy from a single non-contrast CT of abdomen and pelvis is estimated to range from 1 per 500 in a 20-year-old woman to 1 per 1330 in a 60-yearold man. ${ }^{13}$ Patient is exposed to 10 times more radiation than plain film radiography. ${ }^{14}$ Repeat CT study is required due to recurrent nature of disease. An effective radiation exposure of between 20 and $154 \mathrm{mSv}$ occurred in a study due to these repeated exposures..$^{15}$ Other drawbacks of CT are unavailability in many centers, overestimation of calculus size and non-visualization of some calculi such as Indinavir stones. ${ }^{16}$ But sonogram can detect almost all calculi regardless of its composition. ${ }^{2} \mathrm{CT}$ should be avoided in pregnant women, children, young adults, women of child bearing age and patients with repeated bouts of flank pain. ${ }^{17}$

Many studies are now focusing on the use of sonogram in acute ureteric colic. ${ }^{18-20}$ The present study intends to focus on the role of sonography in acute ureteric colic and maximizing its use in detecting ureteric calculi in best possible way.

\section{METHODS}

It is a retrospective study conducted in Dhulikhel Hospital, Kathmandu University Hospital following approval of the institutional review Committee of Kathmandu University School of Medical Sciences(IRC-KUSMS). The study group comprises those patients presenting to the emergency or urology out-patient department from January 2012 to February 2013 with acute unilateral flank pain. The inclusion criteria were 1. Acute ureteric colic less than three days duration 2. Urine analysis report. The exclusion criteria were 1 . Bilateral flank pain 2. Lower abdominal pain 3. Right iliac fossa pain 4. Fever. Total 384 patients, 203 men and 181 women between 7-85 years (mean age of 33.4 years) fell under inclusion criteria and were enrolled in the study following informed consent. Definitive diagnosis of calculus was done based on:

a. Clear visualization of calculus on sonogram

b. Twinkling artifact on Doppler study.

c. History of passage of calculus in urine d. Visualization of calculus in percutaneous nephrolithotomy and ureterolithotomy

The sonograms were performed using ACUSON X 150 and X 300 systems with a CH5-2 convex transducer (Siemens Medical Solution, Mountain View, CA 94043 USA) by one of three radiologists with variable experiences (KSJ, four years experience; SK, two years experience and SR, one year experience).

All the patients were examined in full bladder otherwise no other special preparation was done prior to sonogram due to acute nature of the pain.

Patients were examined in supine position, right lateral, left lateral and prone positions. Prone position was adopted for visualization of proximal ureter between pelviureteric junction and iliac crossing. All the areas were closely examined especially calyces, pelvis, pelviureteric junction (PUJ), ureter, vesicoureteric junction (VUJ) and bladder and any abnormality were carefully noted. One of the most usual findings in the setting of acute flank pain was detection of hydronephrosis. For the sake of simplicity and feasibility; hydronephrosis was graded as mild (Fig1), moderate (Fig 2) and severe (Fig 3). ${ }^{21}$ Hydroureter was detected when an anechoic tubular structure seen in retroperitoneum continuing with the renal pelvis. The dilated collecting system was followed till the level of obstruction. Pelvicalyceal system, PUJ and adjoining ureter were easily detected on lateral position. Remaining portion of proximal ureter was traced in prone position to avoid overlying bowel gas. Distal ureter and VUJ were traced in supine position. Some tricky areas were assessed carefully; iliac crossing, distalmost ureter and VUJ. Iliac crossing was assessed by oblique scanning at the level of iliac vessels with optimum compression. The base of the bladder was examined with the transducer applied firmly and transversely directing inferiorly. Next, the transducer is gently moved superiorly till only the base of the bladder is seen. This is followed by gentle rocking of one end of the transducer slightly superiorly with firm and continuous compression. This maneuver helps to visualize VUJ as well as distalmost ureter. Right side was assessed by superiorly moving the right side of the transducer and left side was assessed by doing it in other way.

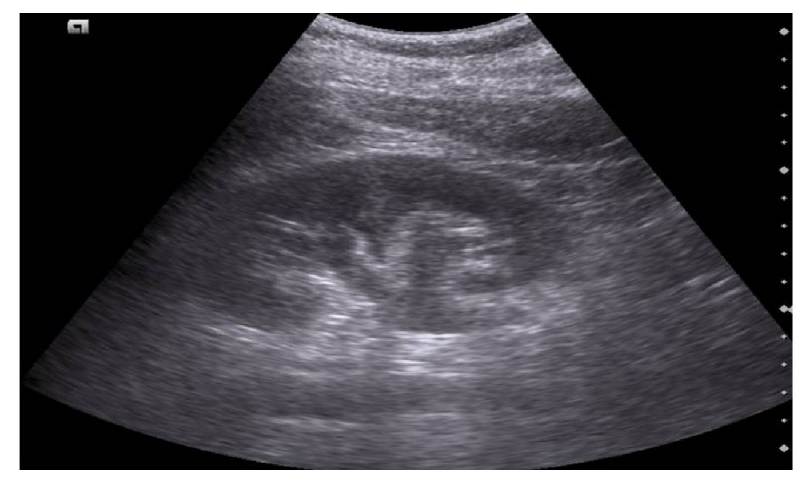

Figure 1. Mild Hydronephrosis. 


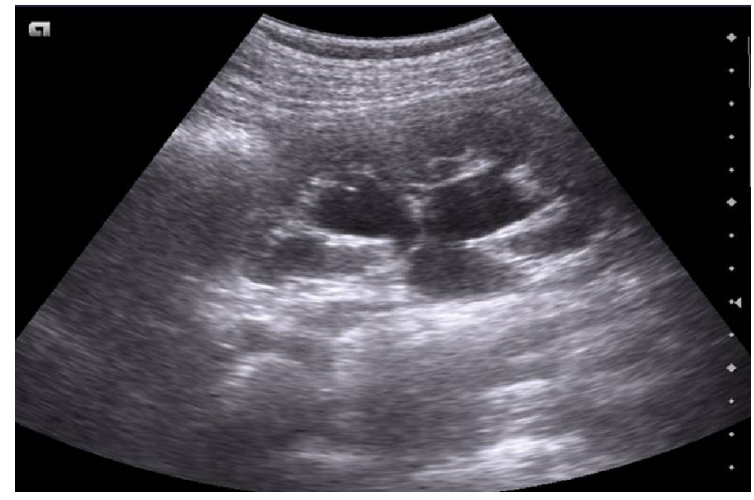

Figure 2. Moderate Hydronephrosis.

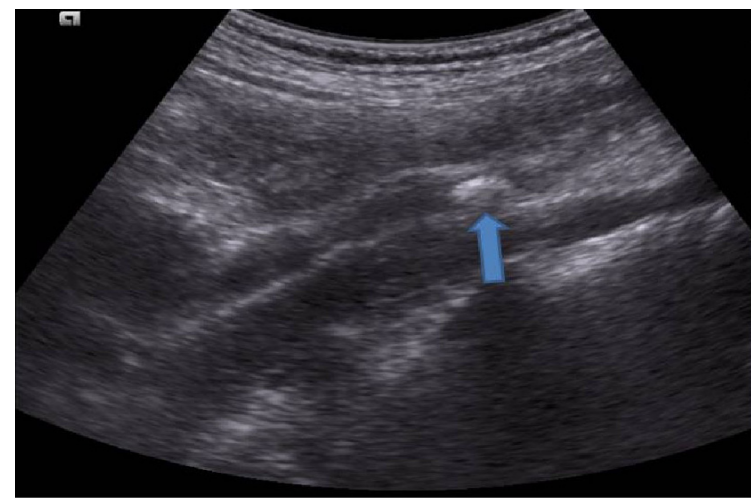

Figure 4. Proximal Ureteric calculus causing mild proximal hydroureter and hydronephrosis.
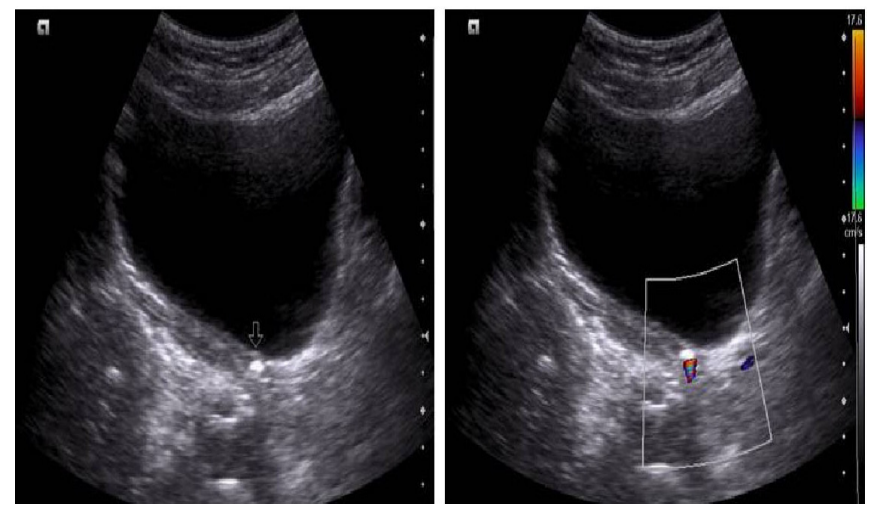

Figure 6. Small left distal ureteric calculus (open arrow) near VUJ. Twinkling artifact seen on Doppler interrogation.

Calculus is detected as an intraluminal echogenic focus with distal acoustic shadowing (Figs 4 and 5). ${ }^{22}$ This was the firm and consistent criterion used for the detection of calculus. Whenever there was a doubt, twinkling artifact was used as an additional diagnostic criterion in color Doppler study (Figs 6 and 7). ${ }^{23,24}$ Strong search for the calculus was performed regardless of status of hydronephrosis and hydroureter though the latter findings helped for easy detection of calculus.

Once the calculus was detected, its size (longest dimension) and location were noted using PUJ, iliac crossing and VUJ as the anatomical landmarks. If more than one calculus was detected, then the exact number of calculi was detected. The longest dimension of the largest calculus was

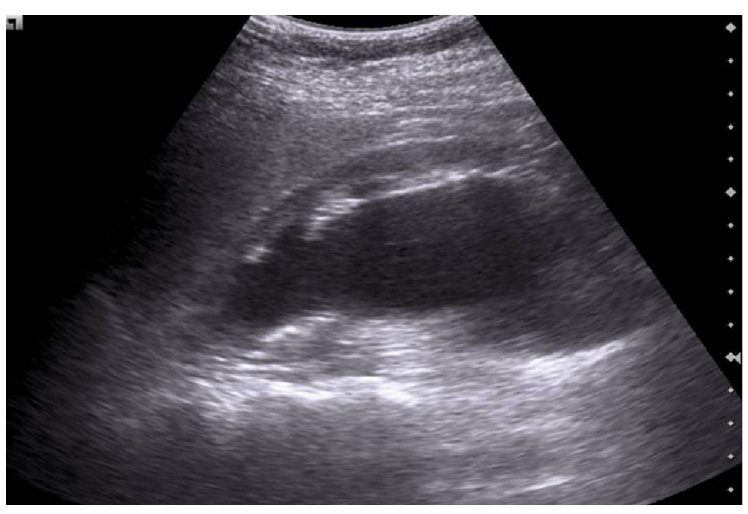

Figure 3. Severe Hydronephrosis.

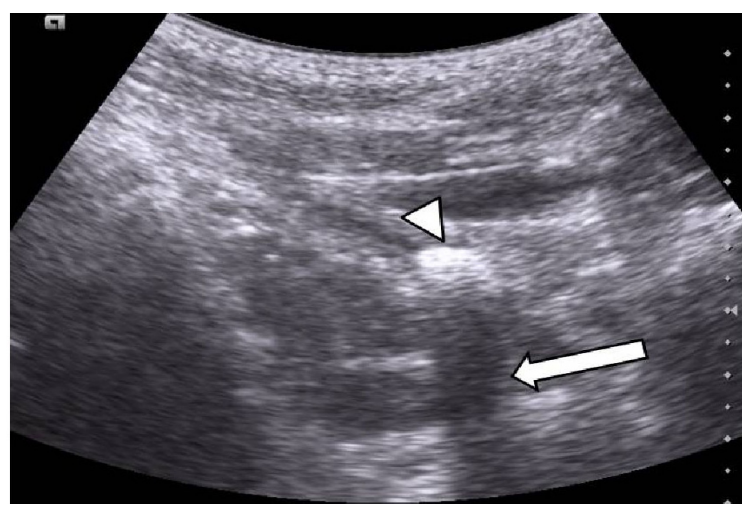

Figure 5. Right distal ureteric calculus. Echogenic shadow (arrowhead) with strong distal acoustic shadowing (arrow).
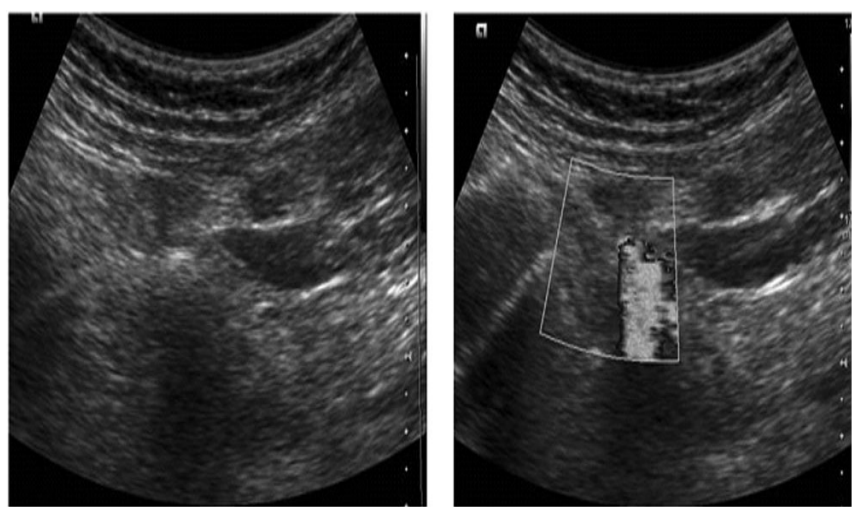

Figure 7. Use of twinkling artifact in doubtful cases of ureteric calculus.

considered for the study purpose.

Urinalysis reports of available patients were obtained and grouped them into two: those with hematuria and those without hematuria.

We then grouped our study sample into:

a. Acute ureteric colic only

b. Acute ureteric colic with hematuria

c. Acute ureteric colic with hydronephrosis

Acute ureteric colic with both hydronephrosis and hematuria. The data were analyzed using SPSS software version 18.0. The subjects' demographic and presenting features have been analyzed with descriptive statistics. A 
logistic regression analysis was done to see the possibilities of detection of calculi with ultrasonography. The sensitivity, specificity, and accuracy have been calculated. The correlation between different independent variables has been analyzed with Spearman's rho. The significance level is considered less than 0.05 .

\section{RESULTS}

Out of 384 patients, 206 (53.6\%) had mild pain and 178 (46.4\%) had severe pain requiring parenteral analgesics (Fig 8). There were 181 (47.2\%) females and 203 (52.9\%) males. Average age of presentation is 33.4 years. The youngest patient was 7 years old and the oldest patient was 85 years. Hydronephrosis was seen in 284 (74\%) patients; 229 with mild, 42 with moderate and 13 with severe hydonephrosis (Fig 9). Fifty five patients (14.3\%) had ureteric colic only, $46(12 \%)$ had ureteric colic with hematuria, 73 (19\%) had ureteric colic with hydonephrosis and 210 (54.7\%) had ureteric colic with hematuria and hydronephrosis. Ureteric calculi were seen in 256 (66.7\%) of patients, of which, 19 had calculi in Pelvis and PUJ; 64 had calculi in the proximal

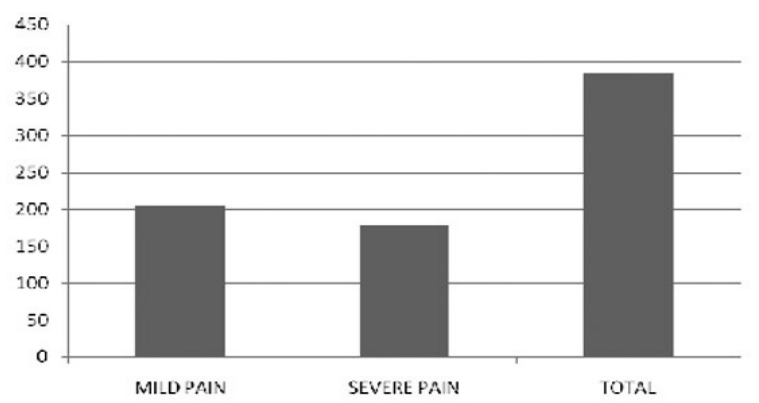

Figure 8. Total patients with ureteric colic, those with mild pain and those with severe pain.

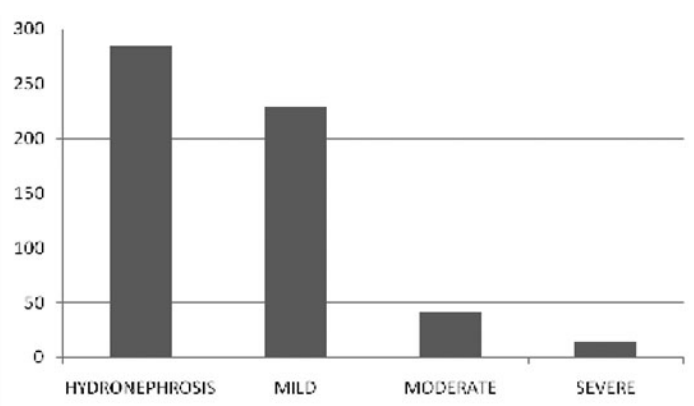

Figure 9. Total patients with hydronephrosis and grading of hydronephrosis.

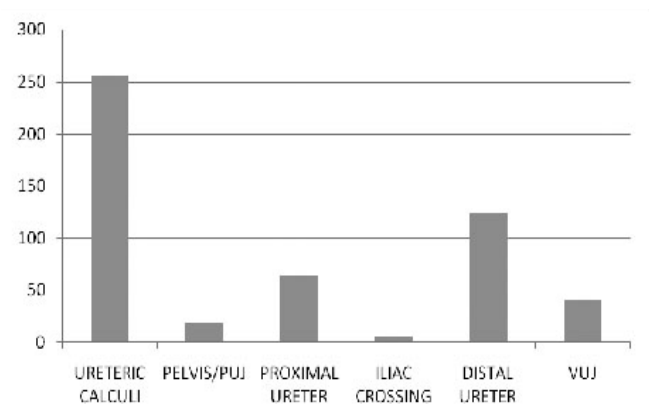

Figure 10. : Location of ureteric calculi. ureter; 6 had in the iliac crossing, 125 in distal ureter and 40 had at the VUJ (Fig 10). Single calculus was found in 241 patients and 14 had multiple calculi. Analyzing the size of calculus, 35 calculi were small $<5 \mathrm{~mm}$; 207calculi were medium $(5-15 \mathrm{~mm})$ and 11 were large $>15 \mathrm{~mm}$. The average size of the calculus is $7.8 \mathrm{~mm}$ whereas, the smallest calculus detected was $2.7 \mathrm{~mm}$ and the largest calculus was $27 \mathrm{~mm}$.

\section{Regression Analysis:To compare odd ratio with Flank pain} only

As shown in the table 1 , the data provides evidence of strong statistical significance of association between flank pain with hydronephrosis and flank pain with hematuria as well as hydronephrosis for the detection of calculi ( $P$ value $<0.001)$. Odds of detecting calculi among those who have flank pain with hydronephrosis is 0.014 times as odds of those having flank pain only $(95 \% \mathrm{Cl}$ : $0.004,0.046)$. Odds of detecting calculi among those who have flank pain with hematuria and hydronephrosis is 0.01 times as Table 1. Regression Analysis: To compare odd ratio with Flank pain only.

\begin{tabular}{llllll}
\hline Variables & Wald & df & Sig & Adjusted OR $(95 \% \mathrm{Cl})$ \\
\hline $\begin{array}{l}\text { Flank Pain with } \\
\text { Hematuria }\end{array}$ & 0.02 & 1 & 0.882 & $1.124(0.238-5.302)$ \\
\hline $\begin{array}{l}\text { Flank Pain with } \\
\text { Hydronephrosis }\end{array}$ & 48.5 & 1 & $0.000 *$ & $0.014(0.004-0.046)$ \\
$\begin{array}{l}\text { Flank Pain with } \\
\text { Hematuria and } \\
\text { Hydronephrosis }\end{array}$ & 67.6 & 1 & $0.000 *$ & $0.010(0.003-0.029)$ \\
*Highly significant & & & & & \\
\hline
\end{tabular}

odds of those having flank pain only ( $95 \% \mathrm{Cl}$ : 0.003, 0.029). However, there is no $t$ association between flank pain with hematuria and detection of calculi ( $P$ value $=0.882$ ).

\section{Sensitivity, Specificity and Accuracy}

Among the 383 patients with independent proof of truly detected calculus $(n=249)$ and truly non-detected calculus $(n=94)$, sensitivity and specificity was calculated. The sensitivity of ultrasonography that is the percentage of occurrences of calculi correctly predicted was found to be $87.98 \%$ (249 of 283 ). The specificity that is the percentage of non- occurrences of calculi correctly predicted was found to be $93.07 \%$ (94 of 101). Overall our predictions were correct in 343 (true detection and non-detection) out of 384 times, giving an accuracy of $89.3 \%$. (Table 2)

Table 2. Sensitivity, Specificity and Accuracy.

\begin{tabular}{|cccc|}
\hline Observed & \multicolumn{3}{c}{$\begin{array}{c}\text { Predicted } \\
\text { Calculus Detection }\end{array}$} \\
& & \multicolumn{2}{c|}{$\begin{array}{c}\text { 1- Yes } \\
\text { 2- No }\end{array}$} \\
\hline Calculus Detection & 1 Yes & 249 & 7 \\
\hline Overall Percentage & 2 No & 34 & 94 \\
\hline Sensitivity & & & 89.3 \\
\hline Specificity & & & 87.98 \\
\hline
\end{tabular}


Table 3. Correlations of calculus in terms of numbers and size.

\begin{tabular}{|c|c|c|c|c|c|c|}
\hline & \multicolumn{2}{|c|}{ Size of Calculus } & \multicolumn{2}{|c|}{ Number of Calculus } & \multicolumn{2}{|c|}{ Degree of Hydronephrosis } \\
\hline & Spearman's rho & $\begin{array}{c}\text { Sig. } \\
\text { (2-tailed) }\end{array}$ & Spearman's rho & $\begin{array}{c}\text { Sig. } \\
\text { (2-tailed) }\end{array}$ & Spearman's rho & $\begin{array}{c}\text { Sig. } \\
\text { (2-tailed) }\end{array}$ \\
\hline Size of Calculus & 1 & - & 0.06 & 0.35 & 0.21 & 0.001 \\
\hline Number of Calculus & 0.06 & 0.35 & 1 & - & 0.70 & 0.000 \\
\hline $\begin{array}{c}\text { Degree of Hydrone- } \\
\text { phrosis }\end{array}$ & 0.21 & 0.001 & 0.70 & 0.000 & 1 & - \\
\hline
\end{tabular}

\section{Correlations}

Degree of hydronephrosis is strongly correlated with the number of calculi ( $P<0.05$, Spearman's rho 0.7). There is a weak but linear relationship between degree of hydronephrosis and size of the calculus $(P<0.05$, Spearman's rho 0.2). There is no correlation between number of calculus and size of calculus $(P>0.05)$. (Table 3$)$

\section{DISCUSSION}

Early evidence in the literatures for the sensitivity of sonogram in detection of ureteric calculi is quite frustrating and ranges between $12-37 \%$ only. ${ }^{25-27}$ But our results achieve far more promising results with an overall sensitivity and specificity of $87.98 \%$ and $93.07 \%$ respectively. This is in consistency with many recent articles. In support to our findings, Patlas et al showed 93\% sensitivity and 95\% specificity in the diagnosis of ureterolithiasis whereas, another study showed an overall sensitivity of $98.3 \%$ and specificity of $100 \% \cdot{ }^{19,20}$ This achievement of high ultrasound sensitivity and specificity for ureteral calculi could be possibly due to newer equipment with compatible hardwares, softwares, algorithms, techniques and a strict preparation protocol including fasting and bladder filling. Hence, sonogram can be very useful imaging in patients with acute ureteric colic.

Calculus detection is more likely when secondary signs of obstruction are present. 1,12,28,29 We have taken hydronephrosis and hematuria as secondary signs of ureteric calculus. There is a strong statistical significance of association between flank pain with hydronephrosis and flank pain with hematuria and hydronephrosis for detection of calculi ( $P$ value $<0.001$ ). Hence, hydronephrosis and accompanying hydroureter are the most determining factors for the detection of calculus probably because the dilated collecting system is easier to trace and hence the obstructing calculus can be well visualized. ${ }^{19}$ Overall sensitivity between 73 to $100 \%$ is found in different reports for the sonographic detection of obstruction of collecting system. ${ }^{17,30}$ In our study, we detected hydronephrosis in $74 \%$ of cases. When hydronephrosis is not present, the collecting system could not be traced and hence calculus could not be detected. This also explains why the calculus detection is least possible among those with flank pain with hematuria and flank pain only. Moreover, hematuria is a nonspecific finding, and the absence of hematuria does not entirely exclude renal colic as a cause of abdominal, pelvic, or flank pain. ${ }^{18,31}$

We did not use ureteral jets and resistive indices of kidneys for the presence or absence of obstruction due to variable results in previous studies. Cronan et al showed that the addition of $\mathrm{RI}$ to renal US did not improve the sensitivity in their studies. ${ }^{28}$ Ureteral jetting is potentially misleading with regard to inference of ureteral patency and it should not serve to exclude the presence of a residual calculus. ${ }^{4,32-34}$ Moreover, we strictly defined positive case as direct visualization of calculus on gray scar imaging and twinkle artifact on Doppler study. We did not define indirect evidences like hydronephrosis as a positive case achieving a very high specificity.

We also detected the number of calculi, location of calculi and size of the calculi which has overall a big role in further management of the patients. Proximal and distally located calculi near PUJ and VUJ can be detected easily but mid ureteric calculi are difficult to detect. ${ }^{18}$ In our study, 125 had calculi in distal ureter and 40 had at the VUJ. Distal ureteric or VUJ calculi are detected in some of the cases even in absence of hydronephrosis due to distended bladder providing a good sonographic window. In the literature, it has been shown that $65 \%$ of acutely presenting calculi impact in distal ureter and VUJ. ${ }^{35}$ Hence sonograms has potential role in the diagnosis and follow up in a substantial number of patients.

Range of calculus sizes that we detected is $2.7-27 \mathrm{~mm}$ with an average size of $7.8 \mathrm{~mm}$. According to literatures, sonography can readily detect calculi of more than $5 \mathrm{~mm}$ in size but not the smaller calculi less than $3 \mathrm{~mm} .{ }^{17,36}$ In our study, there is a weak but linear relationship between degree of hydronephrosis and size of the calculus $(P<$ 0.05 , Spearman's rho 0.2). In their study by Goertz et al the patients with less severe hydronephrosis were less likely to have larger ureteral calculi. ${ }^{37}$ The weak but linear relationship between the size of the calculus and degree of hydronephrosis in our study can be explained in this way. Our study included all the patients with acute ureteric colic less than three days. For hydronephrosis to develop from mild to severe, certain time frame is required. ${ }^{18}$ Hence, regardless of size of the calculus, the degree of hydronephrosis is initially mild. This also explains why majority of patients in our study had mild hydronephrosis 
(80.6\%). We, in addition, also found a very strong correlation $(p=0.000)$ between the degree of hydronephrosis and number of calculi. It means more the number of ureteric calculi, more severe is the hydronephrosis. When hydronephrosis is absent, calculus detection is least likely. This can be explained in two ways. First, the calculus must have passed out unnoticed before sonogram thus relieving hydronephrosis at the time of scan. Second, even if the calculus is retained and not seen, the size of the calculus is small because of linear relationship of calculus size and degree of hydronephrosis as mentioned above. Acute flank pain without hydronephrosis means absent or passed out calculus or a small calculus which is clinically not significant. Patient needs reassurance and follow up scan. A recent series showed that a negative ultrasound in adults presenting with flank pain in the emergency department setting resulted in a low likelihood for urologic intervention within 90 days of their initial visit. ${ }^{38}$ Hence, missing a small calculus is not a big issue as they do not need active intervention. Missing a big calculus is unlikely as they are often associated with hydronephrosis.

However, sonogram is not free of limitations. Three major drawbacks of sonogram are large body habitus, bowel gas and operator dependence. Large body habitus hinders sonographic imaging resulting in poor image quality. This is probably not a big problem due to thin body habitus of our population compared to Western population. ${ }^{20}$ Similarly, due to acute severe pain, patient tends to swallow large amount of air resulting in meteorism. This again hinders sonographic visualization of calculus especially retroperitoneal ureteric calculus. This drawback is inevitable in emergency situations except follow up sonogram with bowel preparation is performed. Some improvement occurs with scanning on full bladder creating a good sonographic window at the pelvis and using newer equipment with better hardware and software facilities. Third drawback is its operator dependence especially experience. This drawback is again inevitable as the experience of the radiologist/ sonologist cannot be changed immediately. The average experience of radiologist in our study is just 2.3 years compared to other studies where the average experience is more than five years. ${ }^{39}$ But still there is not much difference in sensitivity of calculus detection. In our experience, calculus detection in acute flank pain needs combination of laboratory findings, good sonographic equipment, full bladder, sonographic evidence of obstruction and strong determination of radiologist that calculus detection is not very difficult.

In their study Patlas et al found difficulty in some cases to ascertain on CT whether calcification was within the urinary tract or elsewhere, e.g. calcifified phleboliths or a calcified seminal vesicle. ${ }^{19}$ There was one false positive case which was later on found to be a phlebolith. Non-visualization of calculi in some cases was due to passed stones, volume averaging, small stone and/or low attenuation value of the stones. On sonogram, these small focal extraureteral calcified foci are not seen or are very difficult to see thus overcoming false positive cases like in CT scan. Ureteral calculi are seen on ultrasound as a very well defined echogenic focus with distal acoustic shadowing within the dilated ureter.

Sonogram is now reemerging as a first line investigation for the workup of suspected renal colic. Even European Association of Urology Urolithiasis Guideline Panel states that for the diagnosis of renal colic, Ultrasonography should be used as the primary procedure. It is a safe (no risk of radiation), reproducible and inexpensive method of urinary stone detection. Thus CT is not the first line investigation for the acute flank pain in many European and Asian countries. However it is being used persistenly in the United States possibly due to accuracy with CT compared to sonogram, easy availability and large body habitus of patients. ${ }^{40}$

\section{CONCLUSION}

In conclusion, sonogram can be liberally used in all cases of acute flank pain. Hydronephrosis and associated hydroureter is the most significant finding because it paves the way out for the detection of calculus. Absent hydronephrosis is not worrisome because it probably suggests small or passed out calculus requiring no urological intervention.

Future studies regarding the real significance of sonographic absent hydronephrosis or absent ureteric calculus in acute flank pain with follow up prospective study and comparative study between CT and USG regarding their role in decision making among those requiring urological intervention are suggested.

\section{ACKNOWLEDGEMENT}

Our sincere thanks to the following for their support in conducting this study.

Dr. Balaram Malla, Dr. Hemant Bataju, Dr. Sumita Pradhan, Dr. Avish Karmacharya, Dr. Sanu Krishna Shrestha, Dr. Nripesh, Dr. Sujan, Dr. Rajan, Dr. Bibhushan, Dr. Manish, Dr. Jumy, Dr. Sriram, Dr. Bikesh, Ms. Anisha Shrestha, Mrs. Pratikshya Shrestha, Mr. Sitaram Adhikari, Mr. Santosh Mahato, Mr. Satish, Mr. Bhoj and Mrs. Prerana Shrestha Joshi.

\section{REFERENCES}

1. Dunnick RN, Sandler CM, Newhouse JH, Amis ES, Jr. Nephrocalcinosis and nephrolithiasis In: Textbook of uroradiology. 3rd ed. Philadelphia, Pa: Lippincott Williams \& Wilkins; 2001. pg 178-94.

2. Cheng PM, Moin P, Dunn MD, Boswell WD, Duddalwar VA. What the Radiologist Needs to Know About Urolithiasis: Part 1- Pathogenesis, Types, Assessment, and Variant Anatomy. AJR Am J Roent genol. 2012; 198(6): W540-7. 
3. Yilmaz S, Sindel T, Arslan G, Ozkaynak C, Karaali K, Kabaalioğlu A, et al. Renal colic: comparison of spiral CT, US and IVU in the detection ofureteral calculi. Eur Radiol. 1998; 8:212-7.

4. Tamm EP, Silverman PM, Shuman WP. Evaluation of the Patient with Flank Pain and Possible Ureteral Calculus. Radiology. 2003; 228: 319329.

5. Boulay I, Holtz P, Foley WD, White B, Begun FP. Ureteral calculi: diagnostic efficacy of helical CT and implications for treatment of patients. AJR Am J Roentgenol. 1999; 172: 1485-90.

6. Dorio PJ, Pozniak MA, Lee FT Jr, Kuhlman JE. Non-contrast-enhanced helical computed tomography for the evaluation of patients with acute flank pain. WMJ. 1999; 98:30-4.

7. Chen MY, Zagoria RJ, Saunders HS, Dyer RB. Trends in the use of unenhanced helical CT for acute urinary colic. AJR Am J Roentgenol 1999; 173:1447-1450.

8. Vieweg J, Teh C, Freed K, Leder RA, Smith RH, Nelson RH, et al. Unenhanced helical computerized tomography for the evaluation of patients with acute flank pain. J Urol. 1998; 160:679-84.

9. Fielding JR, Fox LA, Heller H, Seltzer SE, Tempany CM, Silverman SG, et al. Spiral CT in the evaluation of flank pain: overall accuracy and feature analysis. J Comput Assist Tomogr. 1997;21:635-8.

10. Smith RC, Verga M, Mc Carthy S, Rosenfield AT. Diagnosis of acute flank pain: value of unenhanced helical CT. AJR Am J Roentgenol 1996;166:97-101.

11. Aslaksen A, Gothlin JH. Ultrasonic diagnosis of ureteral calculi in patients with acute flank pain. Eur J Radiol. 1990; 11:87-90.

12. Sommer FG, Jeffrey RB Jr, Rubin GD, Napel S, Rimmer SA, Benford J, et al. Detection of ureteral calculi in patients with suspected renal colic: value of reformatted noncontrast helical CT. AJR Am J Roentgenol 1995; 165:509-13.

13. Smith-Bindman R, Lipson J, Marcus R, Kim KP, Mahesh M, Gould R, et al. Radiation dose associated with common computed tomography examinations and the associated lifetime attributable risk of cancer. Arch Intern Med. 2009; 169:2078-86.

14. Liu W, Esler SJ, Kenny BJ, Goh RH, Rainbow AJ, Stevenson GW. Lowdose nonenhanced helical $C T$ of renal colic: assessment of ureteric stone detection and measurement of effective dose equivalent. Radiology. 2000; 215:51-4.

15. Katz SI, Saluja S, Brink JA, Forman HP. Radiation dose associated with unenhanced $\mathrm{CT}$ for suspected renal colic: impact of repetitive studies. AJR. 2006; 186: 1120-4.

16. Kishore TA, Pedro RN, Hinck B, Monga M. Estimation of size of distal ureteral stones: noncontrast CT scan versus actual size. Urology. 2008; 72:761-4.

17. Sidhu R, Bhatt S, Dogra VS. Renal colic. Ultrasound Clin. 2008; 3:159170.

18. Moore CL, Scoutt L. Sonography First for Acute Flank Pain? Journal of Ultrasound in Medicine. 2012; 31(11): 1703-11.

19. Patlas M, Farkas A, Fisher D, Zaghal I, Hadas-Halpern I. Ultrasound vs $\mathrm{CT}$ for the detection of ureteric stones in patients with renal colic. $\mathrm{Br}$ J Radiol. 2001; 74: 901-4.

20. Park SJ, Yi BH, Lee HK, Kim YH, Kim GJ, Kim HC. Evaluation of patients with suspected ureteral calculi using sonography as an initial diagnostic tool: how can we improve diagnostic accuracy? J Ultrasound Med. 2008; 27:1441-50.
21. Cochlin DLL, Robinson M. Kidneys \& Ureters. In: Manual of Diagnostic Ultrasound. 2nd ed. Geneva: WHO; 2011. pg 302-3.

22. Tublin M, Thurston W, Wilson SR. The Kidney and Urinary Tract. In: Diagnostic Ultrasound. 4th ed vol 1. Philadelphia: Elsevier Mosby; 2005. pg 344.

23. Lee JY, Kim SH, Cho JY, Han D. Color and power Doppler twinkling artifacts from urinary stones: clinical observations and phantom studies. AJR Am J Roentgenol. 2001; 176:1441-1445.

24. Chelfouh N, Grenier N, Higueret D, Trillaud H, Levantal O, Pariente JL, et al. Characterization of urinary calculi: in vitro study of "twinking artifact" revealed by color-flow sonography. AJR Am J Roentgenol 1998; 171:1055-1060.

25. Erwin BC, Carroll BA, Sommer FG. Renal colic: the role of ultrasound in initial evaluation. Radiology. 1984; 152:147-150.

26. Laing FC, Jeffrey RB, Jr, Wing VW. Ultrasound versus excretory urography in evaluating acute flank pain. Radiology. 1985; 154:613-6.

27. Hill MC, Rich JI, Mardiat JG, Finder CA. Sonography vs. excretory urography in acute flank pain. AJR Am J Roentgenol. 1985; 144:12351238.

28. Cronan JJ, Tublin ME. Role of resistance index in the evaluation of acute renal obstruction. AJR Am J Roentgenol. 1995; 164:377-8.

29. Burge HJ, Middleton WD, McClennan BL, Hildebolt CF. Ureteral jets in healthy subjects and in patients with unilateral ureteral calculi: comparison with color Doppler US. Radiology. 1991; 180:437-442.

30. Ripolles T, Errando J, Agramunt M, Martinez MJ. Ureteral colic: US versus CT. Abdom Imaging. 2004; 29:263-6.

31. Luchs JS, Katz DS, Lane MJ, Mellinger BC, Lumerman JH, Stillman C, et al. Utility of hematuria testing in patients with suspected renal colic: correlation with unenhanced helical CT results. Urology. 2002;59:839-842.

32. Reddy S. State of the art trends in imaging renal of colic. Emerg Radiol 2008; 15(4):217-5.

33. Yang JM, Yang SH, Huang WC. Transvaginal sonography in the assessment of distal ureteral calculi. Ultrasound Obstet Gynecol. 2005; 26(6):658-62.

34. Laing FC, Benson CB, DiSalvo DN, Brown DL, Frates MC, Loughliin KR. Distal ureteral calculi: detection with vaginal US. Radiology. 1994; 192(2): 545-548

35. Eisner BH, Reese A, Sheth S. Stoller ML. Ureteral stone location at emergency room presentation with colic. J Urol. 2009; 182 (1):165-8.

36. Fowler K, Locken J, Duchesne JH, Williamson MR. US for detecting renal calculi with nonenhanced $\mathrm{CT}$ as a reference standard. Radiology 2002; 222:109-13.

37. Goertz JK, Lotterman S. Can the degree of hydronephrosis on ultrasound predict kidney stone size? Am J Emerg Med. 2010; 28(7):813-6.

38. Edmons ML, Yan JW, Sedran RJ, McLeod SL, Theakston KD. The utility of renal ultrasonography in the diagnosis of renal colic in emergency department patients. CJEM. 2010; 12:201-6.

39. Moesbergen TC, Ryke RJde, Dunbar S, Wells JE, Anderson NG. Distal Ureteral Calculi: US Follow up. Radiology. 2011; 260: 575-80.

40. Viprakasit DP, Sawyer MD, Herrell SD, Miller NL. Limitations of ultrasonography in the evaluation of urolithiasis: a correlation with computed tomography. J Endourol. 2012; 26: 209-13. 